\section{A PERIODICAL PAINFUL AFFECTION, BE- LIEVED TO BE LOCATED IN THE LIVER, ITS CAPSULE, OR BOTH, OR POSSIBLY AN IRRIT ATION OF THE CAPSULE OF GLISSON.}

\author{
BY R. HARVEY REED, M.D., MANSFIELD, OHIO.
}

Read in the Section on Practice of Medicine and Materia Medica of American Medical Association, May, I884.

Although the anatomy of the Capsule of Glisson was carefully pointed out by Dr. Francis Glisson in his work on "The Anatomy of the Liver" as early as the middle of the sixteenth century; and although occasionally ever since, medical writers have hinted at diseases of this tunic, yet after a review of many of their writings, and after comparing them with the condition we have designated as above, we are forced to conclude that it is a separate and distinct disease, readily recognizable from associate diseases of the liver, and meriting a distinct place of its own in the catalogue of hepatic maladies.

\section{DEFINITION.}

For the sake of brevity we will only use the term "Irritation of the Capsule of Glisson," to designate this disease which we believe to be a rheumatoid irritation of a part or all of the connective tissue which forms the inner tunic of the liver and envelops the portal vein, hepatic artery and duct, together with the lobules of the liver.

It is characterized by intermitted pain, of a burning, boring, throbbing, darting or lancinating character, occurring usually at night, but unattended with signs of inflammation, by chill,. fever, constipation, loss of appetite or headache.

FREQUENCY.

Whilst quite rare in comparison with the more common hepatic diseases, yet this condition occurs sufficiently often in this region to merit special attention by every practicing physician.

My friend, Dr. J. W. Craig, of Mansfield, Ohio, who has had thirty years of active practice in the profession, and to whom I am indebted for having first called my attention to this condition, reports having treated over one hundred cases in the last twenty years, or an average of five cases a year.

I have seen and treated directly or indirectly twenty-five cases in the last six years, or an average of over four cases a year.

\section{CAUSES.}

The causes which seem most clearly to lead to this disease are sedentary habits.

In fact neither Dr. Craig nor myself have ever met with it in strictly active persons, but invariably in those who had led an inactive life, or were more or less confined in their occupations.

Hence it has been observed to occur more frequently in women than in men, and in persons of middle or advanced age than in children or young persons ; in fact I never knew of it occurring in the latter.
We have met it oftener in persuns engaged in the following occupations or professions than in all others put together; which we have arranged in the relation of their frequency, commencing with the most frequent :

Dressmakers, engineers, ministers, book-keepers, saddlers, printers, shoemakers, tailors, sewing-machine agents, merchants, and one case in that of a boilermaker, and one occurring in a farmer's daughter.

It is seldom found in persons addicted to intemperate habits, but rather in persons of unquestionable temperate habits and with no history of syphilis either constitutional or acquired.

This disease has been noticed to occur most frequently during those times of the year when rheumatism is most prevalent, although it may occur at any time.

\section{SYMPTOMS.}

The premonitory symptoms of this disease come on so insidiously, that the patient is scarcely aware that he is afflicted with more than a "slight colic," or a "touch of neuralgia," or " the cramps," as they will often express it, until it gradually increases in frequency and severity, and perhaps his attention is called to the fact of its periodical returns every few nights, which very greatly disturbs his nocturnal rest.

He generally goes to bed feeling perfectly well, but after a few hours' sleep is awakened with burning, shooting pains in the region of the liver, which keep him awake or compel him to walk his room for an hour or so, or perhaps till morning, before it subsides.

Generally by morning, in the less advanced stages of the disease, the pain subsides and the patient feels as well as usual, and goes to his work thinking "that is all there will be of it," until in a few days he has a repetition of the same, excepting it has increased somewhat in severity, or is more prolonged than the previous attack.

Thus it creeps on gradually, until the attacks of pain become so severe as to warrant his calling a physician, who may find his patient walking the room in agony, or rolling from side to side of the bed, or sitting tailor fashion with the arms folded across the bowels and rocking to and fro. This motion he will sometimes keep up for hours, asserting that " nothing else gives him as much relief," or that "he would die" if he were to stop it.

Upon interrogation, it will be found that these attacks, which at first were weeks apart, are now separated by an interval of a few days only; or perhaps they occur every night, generally coming on about the same time each night, and with but few exceptions after the patient had fallen asleep.

After the attack subsides the patient feels somewhat exhausted, with perhaps a slight tenderness over the hepatic region, but otherwise appears to be in usually good health-so much so that he imagines every attack is certainly the last, until experience induces him to be skeptical of the most favorable symptoms.

If relief is not afforded, these attacks, which at first only last a few minutes, will gradually increase in duration to several hours, or even days, with but very slight interruption.

The pain in these attacks is described as burning, 
boring, cutting, shooting, aching, throbbing or lancinating, generally, however, of the character of the first two, sometimes described as a "coal of fire in their right side."

$I t$ is confined almost entirely to the hepatic region, at times almost entirely to the front and right side, and at others extending around to the back, but seldom any pain is complained of on the left side.

A physical examination reveals a normal or but slightly accelerated pulse, and a normal temperature, a moist, although at times a slightly furred tongue, little or no headache. Occasionally there is a slight sallowness of the skin in the advanced stages of this disease, but there is seldom jaundice.

The appetite is usually good, although at times it is irregular, and occasionally it is poor. Now and then there is vomiting, which generally comes on during a severe attack of pain, when present at all, I having seen it in only one case, and Dr. Craig in but a few.

An examination of the liver reveals but slight enlargement at any time, and often none at all; and but little tenderness even during the attack, and little or no tenderness in the intervals except in cases of long standing.

There is no perceptible hardening of the gland or tendency to a nodulated or so-called "hobnailed" condition.

The bowels are seldom constipated, except in cases which, as patients say, are " naturally so."

The stools are normal in color, regularity and consistency, and after repeated examinations have never been found to contain gallstones.

The urine is generally normal in color: quantity and chemical composition.

The skin is moist, and there is but slight emaciation or general debility, except in very advanced and long continued cases.

DIAGNOSIS.

The diagnosis of this so-called irritation of the capsule of Glisson, whilst somewhat difficult at first, will soon be found to have such distinctive features centered around it, as to render this malady easily distinguished from associate abnormal diseases of the hepatic gland.

The diseases for which it might be mistaken are the "passing of gallstones," "interstitial hepatitis," "congestion of the liver," " perihepatitis," " inflammation of the bile-ducts," "cirrhosis" and "hepatalgia."

If the following differences are borne in mind, there will be little or no danger of mistaking this disease for the passing of gallstones:

\section{PASSING OF GALL- STONES.}

The attacks commence suddenly, and may reach their maximum of severity in the first attack.

The attacks may come on at any time, often just after a meal, a drive over rough roads or violent exercise

There is frequent vomiting.

Colicky, tearing pains.

Marked temporary jaundice may occur from obstruction.

A careful examination of the faces will often reveal gallstones after an attack.

A careful observation of these few differential symptoms will seldom fail to enable the practitioner to make a clear diagnosis between these two conditions. It is possible to confound this disease with interstitial hepatitis, although it is generally very easily distinguished by the following differences:

\section{INTERSTITIAL HEPA- TITIS.}

Generally associated with alcoholic intemperance.

Venous stigmata on the cheeks

Pain and irritation over the liver more or less constant

More or less jaundice.

Nausea and vomiting, especially on first rising in the morning.

Loathing of solid food, particularly in the morning.

Diarrhoea and constipation alternating with each other.

Urine very scanty and dark colored.

Occasional pyrexia.

Often portal obstruction.

Enlargement followed with contraction of the liver.

Often has a distinct syphilitic origin.

Sometines comes on with a chill.

May have ascitis.

Emaciation and general debility.

A dry, harsh skin.

By a comparison of the following diagnostic points, we can readily distinguish this disease from hepatic congestion.

CONGESTION OF THE LIVER.

Enlargement of the liver.

A continued feeling of tightness, or painful distention over the liver.

Jaundice is nearly always present.

Nausea and loss of appetite.

IRRITATION OF THE CAPSULE OF GLISSON.

Seldom associated with alco. holic intemperance.

No venous stigmata on the cheeks.

Pain coming and going in paroxysms.

Sometimes slightly sallow, but seldom jaundiced.

Seldom any nausea or vomiting.

Appetite generally good, or but slightly impaired.

Bowels seldom out of order.

Urine generally normal or nearly so.

Seldom, if ever, any pyrexia.

No portal obstruction.

Seldom any or but slight enlargement, and never followed by contraction of the liver.

Seldom has a clear syphilitic origin.

Never has been known to be preceded by a chill.

Never has ascitis.

Emaciation not marked, and but slight or at times no debility.

Skin not dry and hard.
IRRITATION OF THE CAPSULE OF GLISSON.

Little or no enlargement of the liver.

No feeling of tightness or distention, but a deep burning, boring, lancinating pain of a paroxysmal character.

Jaundice is seldom present.

Seldom nausea or loss of appetite.

\section{CAPSULE OF GLISSON.}

The attacks do not commence suddenly, but come on gradually, increasing in severity with each returning attack.

The attacks nearly always come on at night, seldom immediately after a meal or violent exercise. 
Indigestion, furred tongue and

Vomiting and often diarrhcea, or both.

More or less dyspnoca.

More or less stupidity and drowsiness.

Often signs of obstruction to portal circulation.

Urine scanty and high colored, with more or less bile.

Temporary albumenuria often occurs. interruption until the congestion subsides. headache.

The attacks continue without

Seldom troubled with indigestion. but slightly furred tongue and seldom any headache.

Seldom any vomiting or diar. rhoea.

Seldom ever the slightest dyspnoea.

Seldom any stupidity or drowsiness.

No signs of obstruction to portal circulation.

Urine normal or nearly so.

Albumenuria has never been known to occur.

The attacks come on by paroxysms, between which the patient feels quite well.

Irritation of the capsule of Glisson may also be confounded with perihepatitis, which is more particularly an inflammation of the peritoneal covering of the liver, which inflammation may also extend to Glisson's capsule, which is generally the result, or it may be the consequent of acute peritonitis, or some organic disease of the liver.

It may also be the result of traumatic causes, or the spreading of inflammation from adjacent tissues, and is always ushered in with a chill and followed with fever, pain, and superficial tenderness, together with all the symptoms of inflammation.

On the other hand, in irritation of the capsule of Grlisson, there is no peritonitis, and it is not ushered in with a chill or followed by fever or inflammation, and is not continued without interruption, but is paroxysmal and free from fever and inflammation.

The chief diagnostic points between this disease and "inflammation of the bile ducts" may be briefly summed up as follows:

\section{INFI.AMMATIONOFTHE BIIE DLCTS.}

Generally met with in children or old, gouty persons.

Partial or complete obstruction of the bile ducts.

Jaundice.

Preceded by gastro-duodenal catarrh.

Usual signs of inflammation.

The inflammation usually commences in the mucous membrane of the digestive canal and extends from there to the bile lucts.

Pulse is abnormally slow.

Frequently the stools contain no bile.

IRRITATION OF THE CAPSULE OF GLISSON.

Never met with in children, and not more frequently in old, gouty persons than ordinarily healthy persons of middle age.

No obstruction of the bile ducts.

No jaundice.

Not preceded with gastro-duodenal catarrh.

No symptoms of inflammation.

No inflammation of the diges. tive tract, and is not commumicated from the alimentary canal.

Pulse not particularly changed. The stools are usually normal.

The differential diagnosis of "irritation of the capsule of Glisson" and "cirrhosis of the liver" will require some attention. Whilst it is generally easy, there are points of similarity which might be the means of leading the unguarded astray.
CIRRHOSIS OF THE

IIVER

Is often the result of chronic interstitial inflammation.

Intemperate habits very frequently cause cirrhosis.

Is found in males oftener than in females

Is nearly always fatal.

Is frequently the result of syplilis.

All the general symptoms of acute congestion of the liver, together with those of gastro-enteric catarrh.

Marked constitutional aisturbance.

Frequently there is ascites.

Hæmorrhage from the stomach or intestines

Enlargement of the spleen.

Digestive disturbance very prominent.

As the disease advances the acute pain subsides.

Jaundice in the commencement of the disease, but often more in the advanced stages.

Diminution of hepatic dullness in proportion to the contraction.

Nodulated feeling of the surface of the liver

Dry, harsh skin, with flabby tissues.

Often extensive ecchymosis and hremorrhage from the mucous surfaces.

Irritation of the capsule of Glisson might possibly be mistaken for hepatalgia.

The supply of nerves, however, to this organ, being scanty in comparison to its size, most of which are supplied from the solor plexuses, with a few branches from the pneumogastric, which follow the ramifications of the hepatic artery, would impress us at once, that it is an organ not particularly predisposed to neuralgic affections, and when present at all, will always be found in extremely nervous or hysterical persons, and most generally in females about the time of their menses.

This disease is so rare that Dr. Murchison says: "I do not remember to have met myself with an unmistakable example of hepatic neuralgia."1

Since hepatalgia is a purely functional disease, and occurs so rarely, when it does occur, a careful observation of the general appearance and history of the patient, together with the causes and symptoms of the two diseases, will readily enable the practitioner to diagnose between these two morbid conditions.

DURATION.

Irritation of the capsule of Glisson, if not arrested, may continue for months or even years, with a gen-

\footnotetext{
${ }^{1}$ Clinical Lectures on Diseases of the Liver, p. 485 .
} 
eral tendency to get worse-the attacks coming on more frequently and increasing in severity, with no tendency whatever to get well itself.

\section{PROGNOSIS.}

The prognosis of this disease is exceedingly favorable. Whilst it may linger for months, and in a few cases I have known it to continue for years, neither Dr. Craig or myself have as yet ever seen a fatal case. If, however, it is subjected to proper treatment, it usually subsides in a much shorter time-from a few days to a few weeks, under such treatment, the attacks come on less frequently, continue for a shorter time, and are much less severe each return, until they disappear entirely, and the patient returns to the enjoyment of his usual health.

On the other hand, I have seen these cases resist the most vigorous line of improper treatment for months, and even years, which yielded to suitable remedies in a few days or weeks, and have never had a return of the disease since.

\section{COMPLICATIONS.}

The complications which are most likely to occur with this disease are rheumatism, and occasionally malaria, although any of the diseases to which the liver is subject may be associated with it.

\section{PATHOLOGICAL ANATOMY.}

No fatal cases having occurred either in my own practice or in that of my friends, I have therefore, as yet, nothing to offer on the morbid anatomy of this affection.

\section{TREATMENT.}

I know of no disease which is more satisfactorily influenced by a proper treatment than the one we are now considering, and also know of none which is more tenacious when not properly treated.

The remedies which have given the most satisfactory results in this malady are alkalies combined with a bitter tonic.

The combination most frequently used by Dr. J. $W$. Craig, and one which I have found very satisfactory (excepting its disagreeable taste) is the following:
R Sodii bi-carb............. ziv.

Pulv. hydrastis can..........

M.

S. Use a teaspoonful in two-thirds of a glass of water before eating.

If, however, there is a tendency to constipation, I have found the following to give prompt relief:

B Sodii sulph., C. P..........5v.

Hydrastia sulph.............. gr.v.

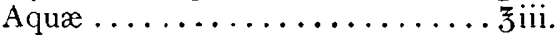

Glycerinæ, q. s. ad........... ऊiv.

M. S. $-3 \mathrm{i}$ before each meal and before retiring.

Sodii et pot. tart. combined with infusion of gentian has given good satisfaction in some cases, or a Seidlitz powder before each meal, followed with a capsule of cinchoniæ sulph. and pepsin after eating, especially if there is any complication of malaria or gastric irritation.

My experience in the large majority of these cases has prejudiced me in favor of the first two formulæ, whicn indicate the general line of treatment I have been most successful with, but which must be modified to suit each particular case.

Where there are marked rheumatic complications good results may be obtained by combining the soda with salicylic acid (that made from the oil of wintergreen is preferred) or salicin, to which may be added the iodide of potassium and ext. of colchicum seed.

Mercurials, as a rule, are not well tolerated-in fact, they have always seemed to aggravate the disease every time I have used them in it.

All stimulants as well as condiments are better avoided, and the patient advised to live on a good nutritious diet, and eat regularly and take plenty of exercise.

Frequent baths of chloride of sodium or the hyposulphite of soda, followed with a brisk rubbing, will very materially assist the treatment, while active exercise should be speedily substituted for the sedentary habits generally practiced by this class of patients.

Frequently the physician is called in the midst of one of these severe attacks of pain, and is urged to give speedy relief.

This can be best accomplished by a hypodermic injection of an eighth or a sixteenth of a grain of sulph. of morphia. Hot fomentations, hot water bags or hot bricks applied over the hepatic region, assist very much in affording relief to the sufferer.

The use of anodynes, however, either internally or by hypodermic injection, should be suspended at the earliest possible moment, for they retard the improvement so desirable in every case.

In order to illustrate this disease, I will report a few cases, which may be fairly considered average cases :

Mrs. A., æt. 38. Had been married for ten or twelve years. Was a large, muscular, robust woman, and had atways enjoyed good health. Had no children, and no history of ever having had a miscar. riage. Had lived most of her life on a farm, but in late years had moved to town and engaged in dressmaking, which kept her closely confined early and late, with but little exercise.

Was first taken ill in 1877 , and suffered very much for several weeks, so that she was compelled to give up her work, and returned home and went at housework. In a few weeks she had improved so much that she returned to the dressmaking again.

In 1878 she was taken ill again, and called on her family physician for relief. The persistence of the trouble compelled her once more to give up her sedentary habits, after which her health soon began to improve; but on returning to it was soon attacked more severely than ever, and feeling discouraged changed physicians.

It was evident from her description of the treatment that her former physician had been treating her for malaria. After she had taken treatment for some time with the second physician, it was evident that he too was not meeting with success, and the author was invited to see her, who was also led astray by the periodicity of the attacks which always came on at night.

Having ascertained that both her medical attendants had freely given her of mercurials and quinine 
together with morphia to control the pain, and without any success, I was at once impressed that there was something peculiar about the case not yet observed.

When first called I found her sitting on a lounge "tailor fashion" with arms folded across the bowels, rocking to and fro and crying with pain which she located in her right side.

It was described as a burning, boring, lancinating distress, over the region of the liver. She informed me she had been feeling pretty well during the day, and had retired feeling comfortable; but in a few hours was awakened with this severe pain. She informed me she had been having these attacks almost every day of late, and that they were getting very much worse. I also learned from my patient that they did not come on with a chill, that her appetite was good and her bowels regular except when she took morphine to relieve the attacks of pain.

I found her pulse slightly excited, but otherwise normal, the tongue was moist and but slightly furred; no aching in the back or limbs.

I found she had been taking morphine so long that it had but little or no effect on her except in large doses, consequently I put her on an anodyne consisting of cannabis indica and hyoscyamus, and applied hot applications over the seat of pain, and supposing it to be of malarial origin, put her on quinia and arsenic.

On returning the next day I found my patient up and around her work and apparently well. I left her some rhubarb to open the bowels, ordered the anodyne discontinued and the quinia and arsenic vigorously pushed.

I obtained some urine for chemical and microscopic examinations, and suspecting gallstones, ordered the feces kept and carefully washed, with a view of capturing any offending material of that character.

On examination I found the urine quite normal, and repeated washings of the stools failed to reveal any gallstones, which increased my faith in the malarial hypothesis.

The second night following I was again called about midnight, and found her repeating the drama of the night before, only if anything worse, which, in spite of all my treatment continued to grow worse.

The case was examined and reëxamined, there was no jaundice, no enlargement of the liver, little or no indigestion, no headache to speak of, no chills, and no fever, or sweating except the perspiration induced by the severe pain, and still these attacks of pain kept on getting worse in spite of all my efforts.

I finally advised counsel and requested the family to call Dr. Craig, of Mansfield (the author was then a resident of West Salem, some thirty miles distant from the above place), who came in a few hours and diagnosed the disease an irritated condition of the capsule of Glisson-a malady which at that time the writer was not at all familiar with.

The doctor advised me to put the patient on sodii bi-carb. combined with pulv. hydras. canadensis, to be given in water previous to each meal; he advised the continuing of the hot applications when the attacks of pain came on, and if absolutely necessary some suitable anodyne until she could endure the attacks of pain without it. Under this treatment my patient made a rapid and complete recovery and now, over six years after, has never had a return of the disease since to my knowledge.

CASE Il. Mr. B., æt. about 35, a saddler by trade, who was under the care of a neighboring physician for months, without any improvement, but rather grew worse. The doctor finally became discouraged and presented him as a clinical case at a meeting of the Northeastern Ohio Medical Association for counsel and advice.

Prof. D. B. Smith, of Cleveland, together with Dr Starr and myself, were appointed to examine his case.

Dr. Bucher stated that his patient was very greatly harrassed with periodical attacks of pain coming on after he had retired, almost every night.

He stated that his patient would work all day at his trade, but after retiring, would be awakened by a severe pain located over the region of the liver, of a burning, shooting character.

These attacks were progressive in severity and frequency until they were occurring almost every night, and were so severe as to deprive him of most of his night's rest.

On inquiry, he revealed no history of syphilis or intemperance, and none of malaria except the periodical nature of his attacks of pain, but lest there should have been some mistake in his history, Dr. B. said he had treated him at different times most vigorously for the first and last maladies, but without relief. He had searched carefully for gallstones in vain, examined the urine and found it normal, had given him liberal doses of mercurials, "in fact" (to use the doctor's words) "I have had him over the materia medica from beginning to end, and nothing I have given him has done him any good.'

After a careful examination it was agreed on by the committee that he had "irritation of the capsule of Glisson," and accordingly he was put on the soda and hydrastis treatment, as previously described in this paper.

In a few weeks after I received a card from the doctor stating that his patient was feeling quite well, that he soon commenced to improve after putting him on the prescribed treatment.

More than a year after I met the doctor, who told me that the patient had made a complete recovery, and was now enjoying good health.

CASE III. Dr. B., æet 75, a clergyman, who had always been a close student, called on the writer in March, I882, and gave the following history:

In December, 1881 , he began to suffer some from distress, which he referred to the stomach, although the appetite remained fair; he informed me that he had been troubled more or less with distress up to February, 1882 , when he discovered that eating lemons gave him relief, until about the first of March, when the burning pain commenced under the short ribs on the right side, generally coming on at night.

Notwithstanding he was under the treatment of his family physician, he observed this pain was steadily increasing, both in severity and frequency, until it came on almost every night; subsiding during the 
day only to awaken him the following night, until it grew so bad that he decided to change his medical adviser and called the writer.

When I first saw him he was suffering intensely with a burning pain in his right side, which, after eliciting the above history, awakened my suspicion of the existence of irritation of the capsule of Glisson. This suspicion was increased when he informed me, he had been able to continue his clerical duties up to the present, although, as he said, he could rest but little on account of the intense agony he was obliged to endure at night.

On examination, I found the pulse normal and the patient free from fever, tongue moist, and but slightly furred, appetite good, stools about normal, and free from gallstones; there was slight constipation at times, urine but slightly changed; some tenderness over the liver, but not much, with very slight enlargement, no jaundice, although his complexion was at times somewhat sallow.

There was no headache or drowsiness, and he was free from backache, or pain in the limbs.

These symptoms, together with his history, confirmed my opinion as to it being a case of irritation of the capsule of Glisson I had to deal with.

I put him on sodii bi-corb. and pulv. hydrastis canadensis, to which I afterward added a tonic of gentian with an occasional laxative dose of sodii et pot tart, which was interchanged with an occasional vegetable laxative.

Hot applications were made over the liver during the attacks of pain, but did not resort to the use of anodynes.

In a few days I found my patient beginning to improve, the attacks of pain becoming less severe, and not so frequent; and in less than a fortnight $I$ was enabled to dismiss him, feeling quite comfortable, the attacks having subsided entirely. He continued the use of the sodii and hydrastis, however, for a few weeks after he was dismissed.

I saw him a few days before I left home, and he reports never having enjoyed better health in his life, and has had no threatening of the return of the disease since.

Were it necessary, I might multiply these reports, but the above cases which have been selected as typical cases, and which have occurred along with many others, at intervals covering a period of six years, will serve to illustrate the disease I am endeavoring to describe.

In presenting this paper I do not expect to escape criticisms. I am fully conscious of its incompleteness, and regret my present inability to accompany it with more thorough and satisfactory investigations than those furnished.

'This paper may, however, serve to call the attention of others to the train of symptoms herein illustrated, and that they may in this manner ve ultimately properly explained.
THE COMMUNITY OF ORIGIN OF DIPHTHERIA, TYPHOID FEVER AND SCARLATINA.'

BY E. O. BARDWELL, M.D., OF MOLINE, ILL.

It will not be expected that the writer of a paper with the above title will be a warm advocate of the theory of specific germs in the etiology of disease, it would hardly be consistent for him to evolve a little germ for each of the three diseases from the same ultimate elements, even for the sake of effect.

I do not wish to be understood as disparaging or discrediting the immense value which the microscope has been, and still is, to scientific medical research, but it is well enough to remember that any valuable acquisition is easily and frequently overvalued by enthusiasts.

The presence in the air of minute organisms has been known for years. A century since, when the microscope was a mere plaything, Goethe in his inimitable work " Faust," made Mephistopheles say, "from air, water, earth, in wet, dry, hot, cold, germs by thousands evolve themselves, had I not reserved fire, I should have nothing apart for myself." The air is pregnant with minute life, and it seems easy to comprehend that disease or its elements being present it might be diffused by these floating particles without creating separate germs for the sole purpose of evolving or transporting each disorder.

According to the germ theory of disease a differ. ent form of bacteria, considered from a morphological standpoint, is essential to the causation of each disease of known bacterial origin. The three divisions of bacteria are, micrococcus, the granular forms; bacillus, rod-like in appearance, and spirillum which exists in the form of twisted threads, and is isot conclusively proven to belong to the bacteria. Micrococcus is divided into many forms by the morphologist, as is also the bacillus, the mutability or stability of these different forms is not yet, however, thoroughly established.

In diphtheria, micrococci and bacilli are found in large numbers in the fauces, the former being the most constant in their appearance. Prof. Gradle, one of the latest writers on the germ theory, and an earnest advocate of its truths admits, however, that "there is as yet no proof that these micrococci are the cause of the disease." 2 In fact experiments would seem to show that so far as known at the present time the presumptive evidence is all the other way.

In typhoid fever a bacillus has been found which has been held to play a part in causation, the most careful observers, however, have failed to find these bacilli in one-half of the cases of enteric fever examined. Koch was one of the observers, and he is probably the best bacilius hunter known at the present time, when we add to this the fact that in no well authenticated case has inoculation experiment propagated the anatomical lesion of typhoid fever in any animal; we must admit that the bacilli causing this disorder have not yet been demonstrated.

1A paper read before the Iowa and Illinois Central District Medical Association, April ro, 1884 . Published by request of the Association.

2 The Germ Theory of Disease. P. $186,188_{3}$. 